\title{
Transformational Leadership: Enabling Factor of Knowledge Management Practices
}

\author{
Hamidreza Yaghoubi ${ }^{1}$, Taghi Mahallati ${ }^{2}$, Amir Safari Moghadam ${ }^{3} \&$ Mohammad Ali Fallah ${ }^{4}$ \\ ${ }^{1}$ Faculty of Management Department, Tehran University, Tehran, Iran \\ ${ }^{2}$ Faculty of Management, Islamic Azad University, Central Tehran Branch, Tehran, Iran \\ ${ }^{3}$ International University of Imam Khomeini, Qazvin, Iran \\ ${ }^{4}$ MSc Public Management, Islamic Azad University, Iran
}

Received: May 13, $2014 \quad$ Accepted: June 6, $2014 \quad$ Online Published: August 29, 2014

doi:10.5539/jms.v4n3p165 URL: http://dx.doi.org/10.5539/jms.v4n3p165

\begin{abstract}
In the knowledge era, knowledge is considered as the most worthwhile asset of the organization. Hence Knowledge management $(\mathrm{KM})$ has a vital role in sustaining competitive advantage and effectiveness of the organization. Successful implementation of KM in organization requires an appropriate context. The importance of human- social context makes transformational leadership as an effective facilitator of KM practices (knowledge creation and knowledge sharing). The primary purpose of the research is investigating the relationship between transformational leadership with KMpractices. The research method is descriptive and correlational. The population of the research consists of 232 person of managers and senior experts of administrative and commercial departments of the NIOPDC. A sample of 144 subjects was selected as statistical sampling. According to the research findings there are significant relationships between transformational leadership with KM practices. These findings support the necessity of adopting more humanistic leadership styles for implementing knowledge management more effectively.
\end{abstract}

Keywords: knowledge management, knowledge creation, knowledge transformation, transformational leadership

\section{Introduction}

In the knowledge-based era, knowledge is the most important capital of organizations that are seeking sustainable competitive advantage. An organization can achieve knowledge and experiences with the help of systematic and comprehensive management and it can use them to protect its success and competitiveness in the long run (Monavarian and Asgari, 2009). The impact of the Knowledge management projects on the overall success of the organization has been widely confirmed (Chennemaneni, 2008). Knowledge Management is seeking for creating and developing knowledge properties of organization. Knowledge management refers to efforts that are done systematically to find, to create, to make access, to apply the intangible capitals of organization and to strengthen the culture of continuous learning and knowledge sharing in organization (Monavarian \& Asgari, 2009). Knowledge management is a complex process that implementing it takes a long time. Implementation and effective use of knowledge management requires precise and clear understanding of factors that affect the process of knowledge management. These factors as a whole are considered as infrastructure (enablers) of knowledge management. Infrastructure of knowledge management includes the components and factors that their existence is essential for improving knowledge management activities in organization (Rahnavard \& Mohammadi, 2009). Human-social nature of knowledge management measures, makes the role of an active and enthusiastic involvement of the human factor in these measures necessary (Asgari, 2011). According to the influence of leadership on creating motivation, involvement and commitment of employees (Robbins, 2000), it seems transformational leadership can have considerable effect on improving the capacity and willingness of individuals to participate in measures of knowledge management.

\subsection{Problem Statement}

Since knowledge management has human-social nature (Chennemaneni, 2008), In this study, knowledge management has investigated a vital and determining roleof human-social factors in improving effectiveness of knowledge management measures among different infrastructures and enablers and it tries to describe the effect 
of one of the most important social factors in organization i.e.Leadership on measures of knowledge management in a valid and reliable way.Leadership role in knowledge management has been emphasized by Cleveland (1985) in his book "knowledge executive" (Cleveland, 1985). Knowledge management should be obvious throughout organization and in all layers of hierarchy (Kouzes \& Posner, 2002). Effective organizations rely on leadership, not leaders (Hubbard, Samuel, \& Cocks, 2002). The role of knowledge leadership is to provide strategic perspective, motivations, establishing effective communication, playing role as a change factor, coaching, appropriate pattern of action and implementing knowledge plan (Debowski, 2006). Knowledge leaders should describe the objectives of knowledge management for all people concerned in a way that they can understand their own role in achieving those objectives (Kouzes \& Posner, 2002). Passion, dynamism and energy of knowledge leaders have an effect on making commitments to others according to knowledge management (Goleman, Boyatzis, \& McKee 2002). Therefore, the success of knowledge management measures requiresthe habitual support by leaders to ensure that the value and results of knowledge management have been internalized in minds of participants (Debowski, 2006). Accordingly, knowledge leaders encourage members of organization by contacting them and establishing relation with them $\mathrm{T}$ identifying individual helps and creating opportunities of growth and development (Kotter, 1998). If plans of knowledge management cannot influence all layers of organization, they are not effective (DeTienne, Dyer, Hoopes, \& Harris, 2004). Given that leaders are effective in all organizational layers, they can play an important and unique role in knowledge management (Kluge et al., 2001).

According to the importance of human-social factors of organization in implementing knowledge management measures (Asgari, 2011) and the effect of leadership factor of employees performance (Rezaiyan, 2000), the topic which is important here is that transformational leadership with emphasis on nurturing individuals and makng supportive environment (Crawford, 2005) how and to what extent can facilitate measures of knowledge management and if this relationship had been confirmed, how we can facilitate knowledge management measures by developing components of transformational leadership?

\section{An Overview of the Theoretical Basics}

In this section in order to achieve reliable and valid basis for explaining the effect of transformational leadership on knowledge management, existing literature in relation to knowledge management (with emphasis on the creation and transfer of knowledge) and transformational leadership are investigated.

\subsection{Knowledge Management}

In today's competitive world, knowledge has become a strategic source of most organizations (Barney, 1991). According to Nonaka, in the current unstable conditions, the only reliable source to gain a sustainable competitive advantage is knowledge (Nonaka, 1994). Therefore Knowledge management has become one of the most important tasks of organizations that are seeking exploitation of their valuable capital (Monavarian \& Asgari, 2007). Knowledge management refers to a systematic and coherent coordination process of extensive activities of organization including acquiring, creating, storing, sharing and applying knowledge by individuals and groups in order o achieve the organizational objectives (Rastogi, 2000).

\subsection{Knowledge Creation}

In fact, knowledge is resulted from experience and skills of employees. It is created when people find new method to do things or to develop substantive knowledge (Bose, 2004). Creating knowledge resulted from social interaction and organizational cooperation (Alavi \& Leidner, 2001). Nonaka describes four models of knowledge creation that are from the interaction between implicit and explicit knowledge at different levels of the organizations: socialization, externalization, combination and internalization (Nonaka \& Takeuchi, 1995).

Table 1. Types of interaction between tacit and explicit knowledge (Nonaka \& Takeuchi, 1995)

\begin{tabular}{lll}
\hline & Totacit knowledge & To explicit knowledge \\
\hline From tacit knowledge & 1 - Socialization & 2 - externalization \\
From explicit knowledge & $4-$ internalization & Cobination \\
\hline
\end{tabular}

\subsection{Knowledge Sharing}

When knowledge is created it must be shared between members of an organization so that it can acts as a basis for innovation and knowledge creation in the future. Creating and sharing knowledge with the aim of creating new knowledge will be possible through cooperation of individuals and synergies resulting from the combination 
of experience and background of organization members (Wood, 2005). Some consider knowledge transfer same as knowledge sharing and have defined it as a process of knowledge spreading throughout the organization. This spreading can be done between individuals, groups, organizations that use any type of communication channels (Alavi \& Leidner, 2001). Other researchersalso consider knowledge transfer as equal as knowledge flow and believe this flow consistes of five main pillars: Know the value of knowledge source, source willingness to share knowledge, media richness of communication channel, the receiver willingness to get knowledge and the ability to recover receiver (Gupta \& Govindarajan, 2000). Davenport and Prusak also know knowledge transfer as knowledge exchange between individuals and groups (Davenport \& Prusak, 1998).

\subsection{Transformational Leadership}

Leadership is the process of influencing followers to achieve the desired results (Robbins, 1379). The quality of this influence is explained based on the behaviors and leader characteristics, perceptions of followers in which the influence process takes place. Leaders build cultures and their main role is influencing others in a way that they eagerly seek pre-determined goals.

Over the past decade, there has been much attention paid to the issue of participation of followers in the leadership process; much attention has been given that now leadership acts as a process in which leader and follower influence each other mutually (Politis, 2001). During the recent decades, the emergence of new approaches to leadership represents a paradigm shift in the interactive methods such as contingency and situational models tovisual, charismatic and transformational models.

The fundamental theory of transformational leadership has been introduced by Bernard Bassand he defined it as the conscious influence process in individual or groups in order to make changes in current situation and functions of organizationas a total concept (Mugheli, 2003). The literature background of transformational leadership goes back to the 1978 and Burns descriptive research on political leaders. Burns stated that transformational leaders have vision and challenge others to do unique things. He defined transformational leadership as a process in which leaders and followers promote each other to a higher level of ethical values and motivation. This is just transformational leaders that can draw necessary routes for new organizations because they are the source of change, they know all about dominant changes in organization and in fact they run the change wave (Robbins, 2000). These leaders empowered followers to take performance beyond expectations and encourage them to seek collective objectives rather than pursuing personal interests. These leaders applyoptimism, charisma, intelligence and a lot of personal abilities to improve others' ideals and lead organization to the highest level of performance (AbediJafari \& Aghaz, 2008).

\subsection{Dimensions of Transformational Leadership}

In this study, to measure transformational leadership, the following indicators have been used (Bryant, Crawford, 2005; 2003). Aspects are:

1) Idealized Influence: idealized influence quality of transformational leaders is inspiring for followers and creates values and valuable concepts in individuals. This charismatic Influence of these leaders changes them asguiding, conceptualizing, motivating and binding factor. Such leaders inspire their own confidence in others. Confidence means believing in oneself. Self-confidence has more likely others' trust.In this way, a sense of trust, admiration and loyalty will create among members of organization and they will try their best to commit the mission (Goh, 2002).

2) Inspirational Motivation: Leaders who communicate with followers benefiting inspirational motivation, determine high standards, explain their own objectives clearly for employees and encourage them to do things behind norms. Inspirational motivation emphasizes on internal feelings and motivations not on daily interaction of leader and follower (Sarvs \& Santra, 2001).

3) Intellectual Inspiration: Transformational Leaders encourage followers to be creative and innovative and they do this by challenging their assumptions, values, traditions and personal beliefs, redefining issues and encouraging to apply new methods. Those methods are used by a transformational leader to encourage followers mentally including: First: Conflict of Duty, i.e., confirming the existence of different views and sometimes opposite in teamwork; Second, the psychological security of team, i.e., growing team in which individuals are encouraged to express their ideas and solutions for problems, even if are different from elites and others' ideas and third: social interaction, i.e., communication process between members (Bass, 1990).

4) Individual Consideration: leader understands followers' need to grow and to satisfy this need and nurturing individuals, will apply coaching style. Such leaders provide the newlearning opportunities along with supportive atmosphere and take care of special needs of each employee (Bass, 1985). Individual consideration 
consists behaviors such as coaching, advising and caring others. Such behaviors value learning and promote expectations of career success (Sosik, 1997).

5) Vision Explanation: Transformational leader provides having clear image of future, mission and ultimate goal understanding and empathy of proud along with trust and respect for followers (Markwarted \& Reynolds, 2002). Leader depicts the desired future and shows how it can be achieved; such leader determines noble objectives and illustrates confidence and a strong willingness to achieve it (Crawford, 2005).

\section{Theoretical Framework}

Given the crucial role of the human factor in knowledge management measures (Asgari, 2011) and the effect of leadership on employee performance (Robbins, 2008), it seems transformational leadership has considerable effect on knowledge management measures. Employees who are more free to create new ideas, to share these ideas with colleagues and to test them, they can be more productive (Singh, 2008). Transformational leadership provides circumstances to facilitate creation, storage, sharing and exploitation of knowledge. These leaders influence organizational cultures a lot. Therefore they can facilitate supporting creative efforts and promoting learning by creating and maintain organizational culture and they can promote organizational creativity. In particular, these leaders provoke their followers to vreating and sharing knowledge by using charisma, intellectual stimulation and personal attention to employees (Bryant, 2003).

In this study, to measure transformational leadership, these five aspects were selected and examined from presented models: idealized influence, inspirational motivation, intellectual inspiration, individual consideration and vision explanation (Bryant, 2003).

Also, in numerous studies have been conducted in the field of knowledge management in different organizations, knowledge creation and knowledge sharing have been considered as two main and key activities of knowledge management (Wang, and Ahmed, 2003). Hence, in this study the effect of these five aspects of transformational leadership on two main activities, namely knowledge creation and knowledge sharing are investigated. Accordingly, based on theoretical studies conducted, the conceptual framework of study is presented as figure 1.

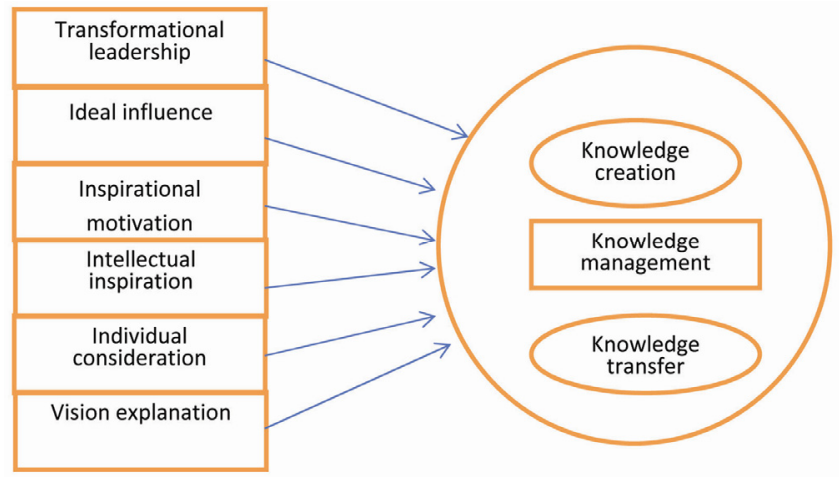

Figure 1. A conceptual model of study

\section{Research Hypotheses}

According to the discussed issues and conceptual model, about the effect of transformational leadership on facilitating knowledge management measures, formulated main hypothesis and sub-hypotheses of this research are as follow:

The main hypotheses: Transformational leadership has positive and significant effect knowledge management measures.

\section{Sub-hypotheses}

1) Idealized influence has positive and significant effect on knowledge management measures.

2) Inspirational motivation has positive and significant effect on knowledge management measures.

3) Intellectual inspiration has positive and significant effect on knowledge management measures.

4) Individual consideration has positive and significant effect on knowledge management.

5) Vision explanation has positive and significant effect on knowledge management measures. 


\section{Research Methodology}

The present study from targeted view is applicable because its finding are used to solve problems inside organization.From quality of collecting data point of view, is considered as descriptive-survey, because it tries to obtain required information of current position of statistical sample by using questionnaire. Also in terms of time period, it is cross sectional and from view of data type is quantitative.

\subsection{The Statistical Territory}

Population studied in this research includesmanagers and employees of the Management and Administration Department and Business Administration Headquarters of National Iranian Oil Products Distribution consisting a total of 232 people. In this study, using the stratified random method, 144 people were selected as sample. To ensure collecting right numbers of questionnaire, 180 questionnaire were distributed between managers and experts and finally 155 questionnaires were collected (11 questionnaires were excluded due to confounding).

\subsection{Data Collection Tools}

Collection tool of field primary data is a 25 question questionnaire that has been used as Likert scale. To measure independent variables i.e., aspects of transformational leadership measure the dimensions of transformational leadership, a questionnaire of Bass study was used (Bass, 1990) and to measure the size of dependent variables i.e., knowledge creation and sharing, a questionnaire of Wang and Ahmad study (2003) was used. To test the reliability of the questionnaire, the primary prototype Including 30 questionnaires were pre-tested and then by using resulted data and with the help of statistical software of SPSS, the confidence coefficient was calculated by Cronbach's alpha that confidence level of $85 \%$ has been obtained.

\subsection{Methods of Data Analysis}

In this study, analysis of obtained data from samplesand checking the presence or lack of simultaneous relationship between variables of structural equation modeling was used.

\subsection{Results of Data Analysis and Hypotheses}

In structural equation modeling, existing relations between traits that were extracted based on the theory, are investigated according to collected data (Kalantari, 2009). In this model, there are 25given variables (survey questions) and 7 latent variables (expressed independent and dependent variables).

After modeling in order to assess the validity of model, special indicators are used including: Chi squareratio to freedom degree that must be less than3, the root of mean square of approximation error must be less than 0.08 and P-value must be less than 0.05 and adjusted fitness index must be greater than 0.9.

To determine the significance of the effect of transformational leadership, significant model and for assessing quality and amount of this effect, standars model is used. About the significance of the obtained numbers, it can be said that sincethe confidence levelof testing hypotheses is 0.95 , numbers will be significant that are not between 1.96 and -1.96 . This means if a number exists between these two, it will not be significant. Figure 2 shows significant effect of transformational leadership on KM measures.

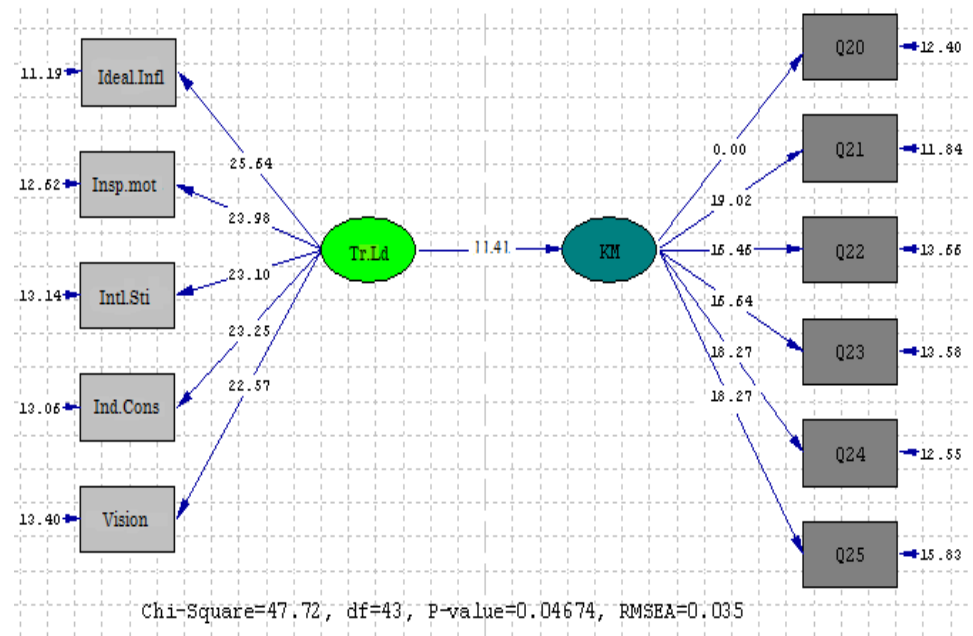

Figure 2. A model for the effect of transformational leadership on knowledge management measures in significant mode 
Based on indicators presented in the following table, we can judge about fitness of this model.

Table 2. Fitness indicators of effects of leadership on knowledge management measures

\begin{tabular}{llll}
\hline Indicators & Allowable amount & $\begin{array}{l}\text { Numbers } \\
\text { obtained }\end{array}$ & Results \\
\hline $\begin{array}{l}\text { Chi-square to freedom degree ratio } \\
\text { (P-Value) }\end{array}$ & $\chi^{2} / \mathrm{df}<3$ & 1.110 & $\begin{array}{l}\text { Goodness of fit } \\
\text { The root mean Square error of }\end{array}$ \\
$\begin{array}{l}\text { P-value less than } 0.05 \\
\text { approximation (RMSEA) }\end{array}$ & $0.08>$ RMSEA $>0.05$ & 0.035 & $\begin{array}{l}\text { Goodness of fit } \\
\text { Fitness index (GFI) }\end{array}$ \\
$\begin{array}{llll}\text { Adjusted Fitness index modified } \\
\text { (AGFI) }\end{array}$ & Greater than 0.9 & 0.93 & Goodness of fit \\
Comparative fitness index (CFI) & Greater than 0.9 & 0.91 & Goodness of fit \\
\hline
\end{tabular}

Indicators of model fitness show appropriateness of measurement model of variables, because a ratio of Chi squareto freedom degree is $1 / 110$ and less than 3 , the root mean square error of approximation (i.e., 0.035) less than allowable amount of 0.08 and P-value (0.0467) is less than 0.05. Based on this model, the effect of transformational leadership on knowledge management proved to be ii/41 and greater than 1.96 and this means the effect is significant.

With the use of standard models we can investigate the effect of transformational leadership on knowledge management measures (research main hypothesis).

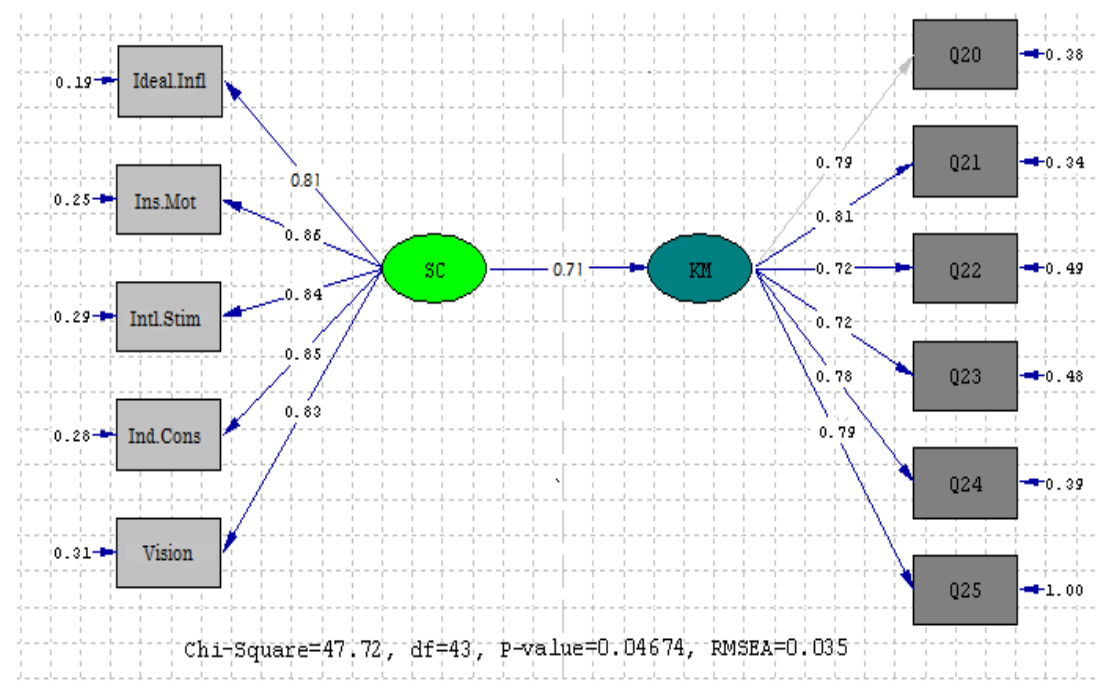

Figure 3. Model for the effect of transformational leadership on knowledge management measures in standard mode

The significant model indicated, the significant effect oftransformational leadership on knowledge management measures.In standard mode it showed leadership explains 71 percent of changes in measures.Thereforemain hypothesis, the significant and positive effect of transformational leadership on knowledge management measures is approved.

\subsection{Sub-Hypothesis Testing of Research}

After confirming the explanatory effect of transformational leadership on facilitating knowledge management measures, we will consider quality and (sub-hypotheses); for this purpose, first the significance model was used to assess the significance of each aspect's effect on KM measures and then by using standard model ,amount and quality of each aspect have been investigated. Since each sub-hypothesis was assessed in an independent model of LISREL and the number of these models was high and behind this article, summary of findings from the analysis of data relevant to these hypotheses are presented in Table 2 and on the basis of it, analysis and concluding will be done. 
Table 3. The results of investigating sub-hypotheses of research

\begin{tabular}{|c|c|c|c|c|c|c|c|}
\hline Hypothesis & Route & $\begin{array}{l}\text { Chi-square to } \\
\text { the degrees of } \\
\text { freedom ratio }\end{array}$ & $\mathrm{p}$-value & $\begin{array}{l}\text { Root mean square } \\
\text { error of } \\
\text { approximation }\end{array}$ & $\begin{array}{l}\text { Standardized } \\
\text { coefficients }\end{array}$ & $\begin{array}{l}\text { Significant } \\
\text { numbers }\end{array}$ & Result \\
\hline 1 & $\begin{array}{l}\text { Significant and positive effect } \\
\text { on the ideal influence on KM } \\
\text { measures }\end{array}$ & 1.96 & 0.000 & 0.090 & 0.58 & 8.23 & confirmed \\
\hline 2 & $\begin{array}{l}\text { Positive and significant effect } \\
\text { of inspirational motivation on } \\
\text { on KM measures }\end{array}$ & 1.74 & 0.023 & 0.071 & 0.62 & 7.45 & confirmed \\
\hline 3 & $\begin{array}{l}\text { Positive and significant effect } \\
\text { of intellectual inspiration on } \\
\text { KM measures }\end{array}$ & 1.80 & 0.007 & 0.061 & 0.67 & 6.39 & confirmed \\
\hline 4 & $\begin{array}{l}\text { positive and significanteffect } \\
\text { on the individual } \\
\text { considerations on } \mathrm{KM} \\
\text { measures }\end{array}$ & 1.58 & 0.028 & 0.052 & 0.64 & 10.36 & confirmed \\
\hline 5 & $\begin{array}{l}\text { Positive and significanteffect } \\
\text { of vision explanation on KM } \\
\text { measures }\end{array}$ & 2.95 & 0.000 & 0.098 & 0.12 & 1.26 & $\begin{array}{l}\text { Not } \\
\text { confirmed }\end{array}$ \\
\hline
\end{tabular}

According to the results presented in Table 2, a significant effect of all aspects of transformational leadership on development of organizational learning has been confirmed, because their amount are not between 1.96 and -1.96. This means these results show these aspects have significant and positive effect on KM measures according to 1-5 hypotheses. These findings with results of previous research that confirmed leadership effect on KM measures, are consistent (Crawford, 2005; Bryant, 2003). Also intellectual inspiration has the most effect on KM measures (0.67).

\section{Results}

The overall pattern of relationships between independent and dependent variables in structural equation modeling were consistent with the stated objectives, the main theory of the effects of transformational leadership on knowledge management measures were approved. Four of these relations examined in the sub-hypotheses of study were positive and significant.

Ideal influence reinforces a sense of respect, trust and loyalty among members of the organization (Crawford, 2005). Such conditions are essential to intensify the willingness of knowledge sharing among members. These findings with the results of previous experiments on the role of social capital (specially trust) are consistent within knowledge sharing (McElroy et al., 2006). Also knowledge sharing can also help to create tacit knowledge (Nonaka \& Takeuchi, 1995). Therefore, ideal influence of leader can facilitate and encourage the creation and sharing of knowledge in organizations. Leaderswho use inspirational motivation when contacting their followers, they can determine high standards for employees and encourage them to do things behind norms (Crawford, 2005). In this case, employees will attempt to find new ways alone or together to perform tasks and to solve problems and this means to create and to share knowledge. Transformational leaders encourage followers to be creative and innovative and they do this by challenging their assumptions, traditions, personal beliefs, redefining issues and encouraging new methods (Crawford, 2005). Creativity development of employees plays an important role in creating new knowledge (Asgari, 2011) because employees can create new knowledge by combining new and effective knowledge (Nonaka \& Takeuchi, 1995). In this case, by improving the capability and experience of the new employees, their willingness to share what they have learned will be more so that to be known as a capable person (Asgari, 2011). Finally, transformational leaders emphasize individual consideration to provide new learning opportunities along with supportive atmosphere (Bass, 1990). Such behaviors value learning, in this case an atmosphere is created where learning and knowledge creation are encouraged and support and intimacy of people make more willing to share knowledge and experiences and to have pubic nurturing.

In general, these results suggest that transformational leadership has positive and considerable effect on creating and sharing knowledge according to developing cooperative behavior, mutual trust, and respect the ideas and feelings of subordinates. Thusit can be said to develop KM measures, it is necessary that leader give enough 
freedom, authority and responsibility to people so that they can gain experience from facts and to be innovative and they can understand whatever happens during performing tasks.In other word, creating and sharing knowledge in organizations are done in an effective way that give freedom to people to think about what they do.

\section{Recommendations}

The results of data analysis has confirmed positive effect of transformational leadership and its aspects on facilitating KM measures; Thus following recommendation are provided in order to make social context to facilitate management measures:

- Strengthening the means of leader influence on employees. Leader influence is based on social aspects of organization. Transformational leaders should consider following to develop their Ideal influence:

Ignoring personal interests because of group interests, showing the strength and self-confidence, communicating with followers by talking about beliefs and essential values, facilitating greater collaboration of followers with leaders by making shared vision and explaining the importance of strong commitment to goals, creating fair competitive atmosphere to develop potential capabilities of employees through material and spiritual bonuses to people and superior groups, empowering socialization rather than individualism through teamwork and giving bonuses based on participation and cooperation of the team members .

- Playing role of cultural modeling. In each organization leaders are model for others. According to what scholars of organizational behavior believe, the responsibility of these leaders is cultural modeling. Enthusiasm and motivation and energy of knowledge leaders, play an important role in making commitment to others. Leaders by emphasizing knowledge culture should support acquiring, transferring, sharing and applying knowledge in organizational operations and make a new atmosphere with their words and acts.

- Consideringinternal control and employee confidence. Addressinginternal control internal makes employees believe that they will be an important part of the organization and are trustworthy. Development of such attitudes can help to promote the professional commitment of knowledge workers in the organization and influence of leaders onemployees.

- Intellectual motivation of employees.To do this in order to reviewing fundamental assumptions and investigating various issues and applying new methods to do things, promoting re-engineering of processes can be useful.Increasingeffective delegation of employees and considering various attitudes, new horizons open about existing approaches to issues and quality of doing tasks and this leads to creating new knowledge and applying in as new solutions and finally provides enabling employees.

- The need to learn cultural diversitymanagement. Creating knowledge requires combining interests, knowledge, skills and expertise. This itself requires recognition and respecting attitude, values and norms differences between people. Thus, promoting cultural diversity by leaders is necessary.

- Drawing promising future. Hopes for the future are consideredas a way to improve employee motivation and commitment. Therefore, it is necessary for leaders to emphasize the importance of providence in order to determine achievable goals, to encourage enthusiasm of employees and make optimisticvision to future in employees.

- linking employees performance with knowledge measures in organization. If participation in the knowledge management should be considered in evaluating employee performance, employees are more likely to create, to share and to apply knowledge.

- Special attention to every employee. Consideration individually and paying attention to employees makes this trust that leader sees everybody and knows about their situation. Thus, leaders should be aware of each of employee's situation and spend enough time to guide and to train them and to meet their needs and to develop capabilities and their creativity. This has a positive effect on learning, development, satisfaction, efforts and commitments of employees.

On the whole it can be said that encouraging employees to exchange knowledge and experiences with each other, group meetings to exchange ideas and views of people, creating a friendly and reliable atmosphere among employees, group discussion for decision- making in specific cases, increasing interaction between managers and employees, facilitating access to information about their tasks, increasing interaction among employees who work in conjunction with each other, are of actions that transformational leadership can apply for facilitating KM measures. 


\section{References}

Abedi Jafari, H., \& Aghaz, A. (2008). Transformational leadership and organizational culture. Journal of Knowledge Management, Spring.

Alavi, M., \& Leidner, D. E. (2001). Review: Knowledge Management and Knowledge Management Systems: Conceptual Foundations and Research Issues. MIS Quarterly, 25(1), 107-136. http://dx.doi.org/10.2307/3250961

Asgari, N. (2011). Providing model of social-human factors' effect on KM measures. Doctoral thesis, Management department, Tehran University.

Barney, J. (1991). Firm Resources and Sustained competitive advantage. Journal of Management, 17(1), 99-120. http://dx.doi.org/10.1177/014920639101700108

Bass, B. M. (1985). Leadership and Performance beyond Expectations. New York: Free Press.

Bose, R. (2004). Knowledge management metrics. Industrial Management \& Data Systems, 104(6), 457-68. http://dx.doi.org/10.1108/02635570410543771

Cleveland, H. (1985). The Knowledge Executive. New York, NY: EP Dutton.

Davenport, T. H., \& Prusak, L. (1998). Working Knowledge: How Organizations Manage What They Know. Boston: Harvard Business School Press.

Debowski, S. (2006). Knowledge Management. John Wiley \& Sons.

Detienne, K. B., Dyer, G., Hoopes, C., \& Harris, S. (2004). Toward a model of effective knowledge management and directions for future research: culture, leadership, and Ckos. Journal of Leadership and Organizational Studies, 10(4), 26-43. http://dx.doi.org/10.1177/107179190401000403

Farajollah, R., \& Asghar, M. (2009). Identifying the key factors in the overall success of a system of knowledge management in schools and higher education centers of Tehran. Journal of information Technology management, 1(1), 37-52.

Goh, S. C. (2002). Managing effective knowledge transfer: an integrative framework and some practice implication. Journal of Knowledge Management, 6(1), 23-30. http://dx.doi.org/10.1108/13673270210417664

Goleman, D., Boyatzis, R., \& McKee, A. (2002). The New Leaders: Transforming the Art of Leadership into the Science of Results. London: Time Warner.

Gupta, A. K., \& Govindarajan, V. (2000). Knowledge Management's Social Dimension: Lessons from Nucor Steel. Sloan Management Review, 42(1), 71-80. Available from $\mathrm{http}$ //sloanreview.mit.edu/article/knowledge-managements-social-dimension-lessons-from-nucor-steel/

Hubbard, G., Samuel, D., \& Cocks, G. (2002). The First XI: Winning Organizations in Australia. Brisbane: Wiley.

Kalantari, K. (2009). Structural equation modeling in social-economic research. Consulting engineers of landscape publications.

Kluge, J., Stein, W., \& Licht, T. (2001). Knowledge Unplugged. Bath: Bath Press. http://dx.doi.org/10.1057/9780333977057

Kotter, J. P. (1998). John P. Kotter on What Leaders Really Do. Boston, MA: Harvard Business School Press.

Kouzes, J. M., \& Posner, B. Z. (2002). The Leadership Challenge (3rd ed.). San Francisco, CA: Jossey-Bass.

McElroy, M. W., Jorna, R. J., \& Engelen, J. (2006). Rethinking social capital theory: a knowledge management $\begin{array}{lllll}\text { perspective. Journal of Knowledge } & \text { Management, 10(5), 136. }\end{array}$ http://dx.doi.org/10.1108/13673270610691233

Monavarian, A., \& Asgari, N. (2007). Structural and content dimensions of knowledge-based organization. Tehran, The National Conference on Knowledge Management.

Monavarian, A., \& Asgari, N. (2008). The organization of the industrial, information and knowledge age. Tehran: Tehran University Press.

Mugheli, A. (2001). Designing a pattern of transformational leadership in administrative agencies of Iran. Journal of Knowledge Management, Fall. 
Nonaka, I. (1994). A dynamic theory of organizational knowledge creation. Organization Science, 5(1), 134-139. http://dx.doi.org/10.1287/orsc.5.1.14

Nonaka, I., \& Takeuchi, H. (1995). The Knowledge Creating Company: How Japanese Companies Create the Dynamics of Innovation. New York: Oxford University Press.

Politis, J. D., \& Crawford, J. (1998). The relationship between leadership self-management behavior, self-worker leadership behavior and Desirable Outcomes. 6th Annual Australian Self-Managed Work Teams Conference, Sydney.

Rezayian, A. (2000). Management of organizational behavior. Samt publication.

Robbins, S. P. (2000). Principles of Organizational Behavior. Publications of cultural research Office.

Wang, C., \& Ahmed. (2003). Structural dimensions based Forknowledge Organizations. Business Measures Excellence, 7(1), 51-62. http://dx.doi.org/10.1108/13683040310466726

Wood, C. (2005). An empirical examination of factors Influencing work-unit effectiveness in knowledge management organization. The University of Texas at Arlington.

\section{Copyrights}

Copyright for this article is retained by the author(s), with first publication rights granted to the journal.

This is an open-access article distributed under the terms and conditions of the Creative Commons Attribution license (http://creativecommons.org/licenses/by/3.0/). 